\title{
Rapid Ultrasonic-Assisted Soldering of AZ31B Mg Alloy/6061 Al Alloy with Low-Melting-Point Sn-xZn Solders Without Flux in Air
}

\author{
Zhi-Wei Lai ${ }^{1,2,3} \cdot$ Zhe-Yuan Huang $^{2,6} \cdot{\text { Chuan } \text { Pan }^{3} \cdot \text { Hui-Qiao } \mathrm{Du}^{4} \cdot \text { Xiao-Guang Chen }^{2} \cdot \text { Lei Liu }^{2} \cdot \text { Wei-Ming Long }}^{5}$. \\ Gui-Sheng Zou ${ }^{2}$
}

Received: 8 February 2018/Revised: 16 March 2018/Published online: 16 May 2018

(C) The Chinese Society for Metals and Springer-Verlag GmbH Germany, part of Springer Nature 2018

\begin{abstract}
A novel ultrasonic-assisted low-temperature soldering was developed to join AZ31B Mg alloy and $6061 \mathrm{Al}$ alloy with a series of $\mathrm{Sn}-x \mathrm{Zn}$ solders. The average maximum shear strength of the joints reaches up to $87.5 \mathrm{MPa}$ at soldering temperature of $300{ }^{\circ} \mathrm{C}$ under ultrasonic assistance for only $5 \mathrm{~s}$ using $\mathrm{Sn}-20 \mathrm{Zn}$ solder. The fracture path propagates completely in the soldering seam. The results indicate that the microjet generated by ultrasonic pressure in liquid solder could strike and splinter the $\mathrm{Mg}_{2} \mathrm{Sn}$ intermetallic compounds into small pieces, which contributes to the enhancement of the joint strength. In addition, the primary $\mathrm{Al}(\mathrm{Zn})$ solid solution phase formed during cooling stage could also strengthen the joint due to the prevention of microcracks propagation.
\end{abstract}

Keywords Ultrasonic-assisted soldering · Ultrasonic effect mechanism · Microjet · Intermetallic compound distribution · Solid solution $\cdot$ Joint strengthening

\section{Introduction}

Magnesium (Mg) and aluminum (Al) alloys, compared with conventional metal materials, have some unique advantages such as low density, good high strength-toweight ratio, dimensional stability, machinability and low

Available online at http://link.springer.com/journal/40195

Gui-Sheng Zou

zougsh@tsinghua.edu.cn

1 School of Materials Science and Engineering, Tsinghua University, Beijing 100084, China

2 Department of Mechanical Engineering, Tsinghua University, Beijing 100084, China

3 China Iron \& Steel Research Institute Group, Beijing 100081, China

4 Beijing Spacecraft Manufacturing Factory, Beijing 100190, China

5 The State Key Laboratory of Advanced Brazing Filler Metals and Technology, Zhengzhou Research Institute of Mechanical Engineering, Zhengzhou 450001, China

6 College of Materials Science and Engineering, Shanxi Key Laboratory of Advanced Magnesium-Based Materials, Taiyuan University of Technology, Taiyuan 030024, China casting costs. Hence, it has gained great attention in academic research as well as industrial applications $[1,2]$. Joining of $\mathrm{Mg}$ alloy/Al alloy dissimilar materials could not only optimize material application but also reduce the weight of the structures. Therefore, the investigation of these alloys joining is significant [3].

A variety of joining methods, such as tungsten inert gas welding (TIG) [4], friction stir welding [5], diffusion bonding [6,7] and explosive welding [8] have been reported to join $\mathrm{Mg}$ and $\mathrm{Al}$ alloys. However, $\mathrm{Mg}-\mathrm{Al}$ intermetallic compounds $\left(\mathrm{Al}_{3} \mathrm{Mg}_{2}, \mathrm{Al}_{12} \mathrm{Mg}_{17}\right.$, etc.) will be inevitably formed in the joint because the temperature during joining is higher than that of $\mathrm{Mg}-\mathrm{Al}$ intermetallic reaction point. To some extent, the microcrack initiation and propagation will appear near the continuous brittle $\mathrm{Mg}-\mathrm{Al}$ intermetallic compounds (IMCs), which will seriously deteriorate the mechanical property of $\mathrm{Mg} / \mathrm{Al}$ joint [9-11]. Therefore, it is necessary to avoid the formation of $\mathrm{Mg}-\mathrm{Al} \mathrm{IMCs}$ by reducing the joining temperature lower than the $\mathrm{Mg}-\mathrm{Al}$ intermetallic reaction point. Compared with those methods above, brazing or soldering has many advantages in joining $\mathrm{Mg}-\mathrm{Al}$, due to its variable solders and bonding temperature selection [12-14]. Wang et al. [15] has designed a series of $\mathrm{Sn}-x \mathrm{Zn}$ solders for joining $\mathrm{Mg} / \mathrm{Al}$ dissimilar metals. In their study, no $\mathrm{Mg}-\mathrm{Al}$ IMCs 
were observed in brazing seam by using $\mathrm{Sn}-30 \mathrm{Zn}$ solder at $360{ }^{\circ} \mathrm{C}$. However, the $\mathrm{Al}$ alloy sheet had to be pretreated by hot-dipping technique to be combined with the solders, and the soldering process had to be conducted with the protection of argon gas in a tubular resistance furnace, making this process complex and thus limiting its industrial application.

Compared with conventional vacuum brazing, ultrasonic-assisted joining methods (brazing, soldering and transient liquid phase bonding, etc.) could be carried out in air ambient, because the "ultrasonic effect" is able to remove the oxide without vacuum and flux and it also can accelerate the reaction rate effectively [16-18]. These methods have been widely studied in the lightweight materials such as $\mathrm{Al}$ alloy/Al matrix metal composites (MMCs) [18-20], Mg alloy/Mg MMCs [21, 22], and excellent joint properties have been achieved. Huang et al. [22] designed a novel $\mathrm{Zn} / \mathrm{Al} / \mathrm{Zn}$ compound interlayer to join $\mathrm{SiC}$ particles-reinforced $\mathrm{Mg}$ MMCs using ultrasonicassisted transient liquid phase bonding method, where the bonding seam completely translated into full $\mathrm{Mg}$ solid solution and the joint strength reached up to $87.5 \%$ of base material strength. During the joining of the same material, we hope to obtain the joint microstructure more similar to the base material in order to ensure the consistency of mechanical property or other function properties (electricity, corrosion resistance, etc.) of the joints.

However, for the dissimilar metals joining, it is difficult to obtain the joint microstructure that is the same to any one of the base materials. It is more significative and feasible to focus on optimization of the phase morphology and the distribution of IMCs in the joint. In other words, we need to eliminate the harmful IMCs or smash them from continuous layer into small pieces to reduce the risk of brittle fracture. Fortunately, it has been reported in our previous studies that [23] high-strength $\mathrm{Mg}-\mathrm{Al}$ joint was obtained using pre-coated $\mathrm{Zn}-\mathrm{Al}$ solders on the $\mathrm{Al}$ sheet for a short time of ultrasonic assistance $(3 \mathrm{~s})$ at $340{ }^{\circ} \mathrm{C}$. This research provided a novel and efficient method to join $\mathrm{Mg} / \mathrm{Al}$ dissimilar metals. However, there are still some aspects needed to be further improved and studied: (1) These bonding temperatures are still relatively high which might induce the residual stress concentration and the reduction of base material strength after the soldering thermal cycle [24]; (2) The mechanism of ultrasonic effect in joining process, especially the affection of ultrasonic in distribution of IMCs morphologies, is uncertain.

Therefore, in this study, a lower melting-point $\mathrm{Sn}-x \mathrm{Zn}$ solder with the base element $\mathrm{Sn}$ and the additional element Zn with 9, 20 and 30 wt\%, respectively, was designed. The Sn-based solders are suitable to join temperature-sensitive alloys having low melting point [25], and the addition of $\mathrm{Zn}$ can strengthen the interfacial bonding due to high mutual solubility of $\mathrm{Al}$ [26]. The $\mathrm{Al} / \mathrm{Mg}$ dissimilar alloys are rapidly joined with the assistance of ultrasound, and the optimized solder is selected based on the joint strength. The effects of ultrasonic assistance and joint formation mechanism were investigated based on the optimized solders by controlling varied ultrasonic assistance time.

\section{Experimental}

The base materials are AZ31B Mg alloy and $6061 \mathrm{Al}$ alloy sheets with dimension of $45 \mathrm{~mm} \times 10 \mathrm{~mm} \times 3 \mathrm{~mm}$. The chemical compositions of base materials are shown in Table 1. The sample surfaces were ground with $\mathrm{SiC}$ sand paper to $1000 \#$ and ultrasonically cleaned with acetone for 15 min before soldering. The schematic illustration of the ultrasonic-assisted soldering process is shown in Fig. 1a. $\mathrm{Mg}$ alloy sheet was placed on the top of $\mathrm{Al}$ alloy sheet with $3 \mathrm{~mm}$ overlapping length and $200 \mu \mathrm{m}$ gap. The solder was placed on the edge of the overlapping zone on the bottom of Al alloy sheet. During the soldering process, the ultrasonic horn was loaded on the $\mathrm{Al}$ alloy sheet with a constant pressure of $0.15 \mathrm{MPa}$. The frequency and amplitude of ultrasound are $20 \pm 0.1 \mathrm{kHz}$ and $10 \mu \mathrm{m}$, respectively. High-frequency induced heating device was used to heat the soldering system, and the heating speed is $20{ }^{\circ} \mathrm{C} \mathrm{min}{ }^{-1}$. The parameters used in the process are shown in Fig. 2. The soldering parameters are divided into two processes: (I) the samples soldered with pure $\mathrm{Sn}, \mathrm{Sn}-$ 9Zn, Sn-20Zn and Sn-30Zn are under the ultrasonic assistance for $5 \mathrm{~s}$ after heated to $260,230,300$ and $340{ }^{\circ} \mathrm{C}$, respectively; (II) the samples soldered with $\mathrm{Sn}-20 \mathrm{Zn}$ are under ultrasonic assistance for 1, 3, 5, 10 and $15 \mathrm{~s}$, respectively, after heating to $300{ }^{\circ} \mathrm{C}$.

The cross sections of the joints were cut and prepared using a standard polishing technique. The microstructures were observed using scanning electron microscopy (SEM, Quanta 200F) equipped with an energy-dispersive X-ray spectroscopy (EDS) analysis system. The phase constitutions of the joint were analyzed using a D/max 2500 X-ray diffraction (XRD). The shear strength of the joints was tested using electronic universal testing machine (ZWICKZ020) at a loading speed of $2 \mathrm{~mm} \mathrm{~min}^{-1}$. The testing schematic diagram of which is shown in Fig. $1 b$.

Table 1 Chemical compositions of AZ31B Mg alloy and $6061 \mathrm{Al}$ alloy (wt\%)

\begin{tabular}{llllll}
\hline Base metal & $\mathrm{Al}$ & $\mathrm{Si}$ & $\mathrm{Zn}$ & $\mathrm{Mn}$ & $\mathrm{Mg}$ \\
\hline AZ31 & $2.5-3.5$ & 0.1 & $0.5-1.5$ & $0.2-0.5$ & $\mathrm{Bal}$. \\
6061 & 98 & 0.5 & 0.0005 & 0.0038 & 0.97 \\
\hline
\end{tabular}


(a)

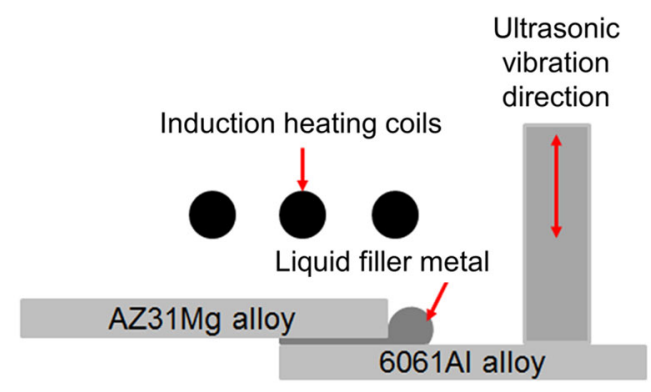

(b)

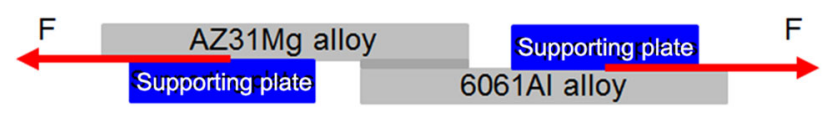

Fig. 1 Schematic diagrams of ultrasonic-assisted soldering process $\mathbf{a}$ and shear strength test $\mathbf{b}$

\section{Results and Discussion}

\subsection{Soldering Seam Microstructures and Mechanical Properties with Different Zn Contents}

The SEM images of the joint soldered with a series of Sn$x \mathrm{Zn}$ solders for $5 \mathrm{~s}$ ultrasonic assistance of the soldering process I are shown in Fig. 3. The widths of joints soldered with pure Sn, Sn-9Zn, Sn-20Zn and Sn-30Zn are 200, 214, 240 and $293 \mu \mathrm{m}$, respectively. The increase in the joint width is mainly attributed to the increasing dissolution of $\mathrm{Mg}$ and $\mathrm{Al}$ base metal into the liquid solder. The phase existing in the pure Sn soldered joint (Fig. 3a) is mainly $\mathrm{Sn}-\mathrm{Mg}$ eutectic phase with some $\mathrm{Mg}_{2} \mathrm{Sn}$ blocky phase. There is no Al-based phase observed in the soldering seam, because $\mathrm{Al}$ element only has solid solubility of 1 at.\% in $\mathrm{Sn}$ at $225^{\circ} \mathrm{C}$ according to $\mathrm{Al}-\mathrm{Sn}$ binary phase diagram [27]. This solubility is too small to form unique Al-based phases. It has been reported that the pure Sn was used to solder $2024 \mathrm{Al}$ alloy at $300{ }^{\circ} \mathrm{C}$ but the bonding at the interface is weak [28]. On the $\mathrm{Mg}$ side, there is a continuous thin layer of $\mathrm{Mg}_{2} \mathrm{Sn}$ phase. As the $9 \mathrm{wt} \% \mathrm{Zn}$ is added into the solder (Fig. $3 b$ ), the needle $\eta$-Zn phase appeared and the black spherical $\mathrm{Al}(\mathrm{Zn})$ solid solution phase emerged in the joint, which indicates that the addition of $\mathrm{Zn}$ promoted the dissolution of $\mathrm{Al}$.

Figure $3 \mathrm{c}$ shows the microstructures of joint soldered with $\mathrm{Sn}-20 \mathrm{Zn}$. Some blocky $\mathrm{Mg}_{2} \mathrm{Sn}$ phases form in whole soldering seam, indicating that more $\mathrm{Mg}$ is dissolved and reacts with $\mathrm{Sn}$. With the increase of $\mathrm{Zn}$, the $\eta-\mathrm{Zn}$ phase grows up and the amount of $\mathrm{Al}(\mathrm{Zn})$ solid solution increases and migrates into the whole soldering seam. Figure $3 \mathrm{~d}$ shows the microstructures of the joint soldered with $\mathrm{Sn}-$ $30 \mathrm{Zn}$ at $340{ }^{\circ} \mathrm{C}$. A large amount of $\mathrm{Mg}$ is dissolved into the soldering seam, forming the continuous $\mathrm{Mg}_{2} \mathrm{Sn}$ phase. The $\mathrm{Al}(\mathrm{Zn})$ solid solution further increases, and the $\mathrm{Al}$ grain boundaries are eroded. As shown in Fig. 4, the shear strength of the joints with pure Sn was only $44.3 \mathrm{MPa}$. As $\mathrm{Zn}$ content increases to $9 \mathrm{wt} \%$, the shear strength of the joint increases up to $66.8 \mathrm{MPa}$. It is significant that the maximum strength of $87.5 \mathrm{MPa}$ is obtained when the $\mathrm{Sn}-$ $20 \mathrm{Zn}$ solder is used to joining $\mathrm{Mg}-\mathrm{Al}$ at $300{ }^{\circ} \mathrm{C}$ without flux in air ambient. Compared with other methods reported, this joint strength of $\mathrm{Mg}-\mathrm{Al}$ joints is higher and the joining temperature is much lower (joint shear strength $\sigma=70.73 \mathrm{MPa}$; temperature $T=360{ }^{\circ} \mathrm{C} ; \mathrm{Sn}-30 \mathrm{Zn}$; argon gas protection ambient) [15]. However, the shear strength of the joints soldered with $\mathrm{Sn}-30 \mathrm{Zn}$ solder drops to 56.9 MPa. Therefore, it can be concluded that the $\mathrm{Sn}-20 \mathrm{Zn}$ alloy is relatively much more suitable to be used to join $\mathrm{Mg}-\mathrm{Al}$ structures due to the high joint strength obtained and moderate soldering temperature used.
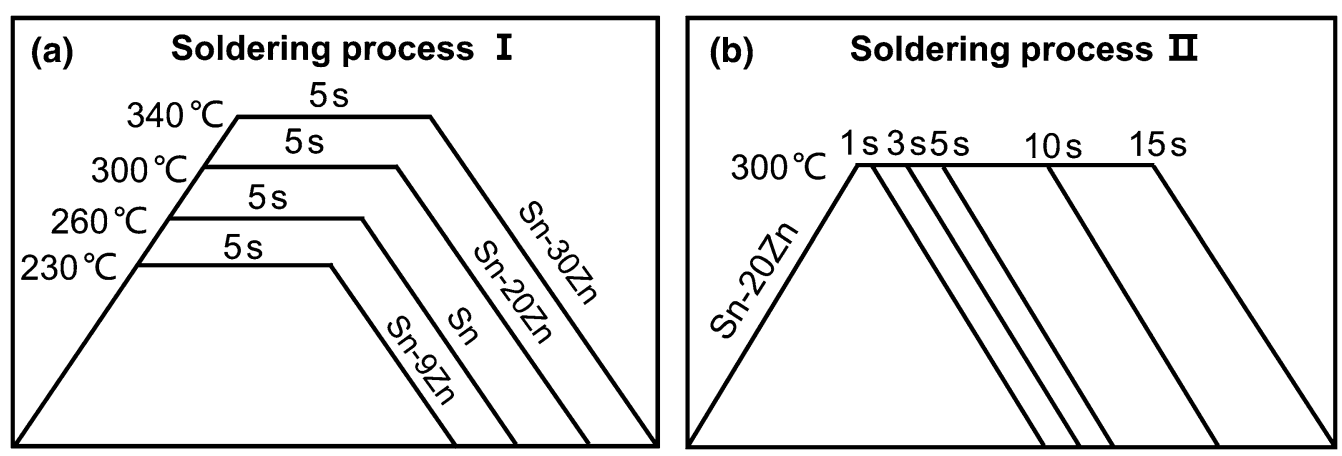

Fig. 2 Schematic diagrams of technological process parameters for different $\mathrm{Zn}$ contents of $\mathrm{Sn}-x \mathrm{Zn}(x=0,9,20,30$, wt $\%)$ solders a and varied ultrasonic assistance time using Sn-20Zn solder b 

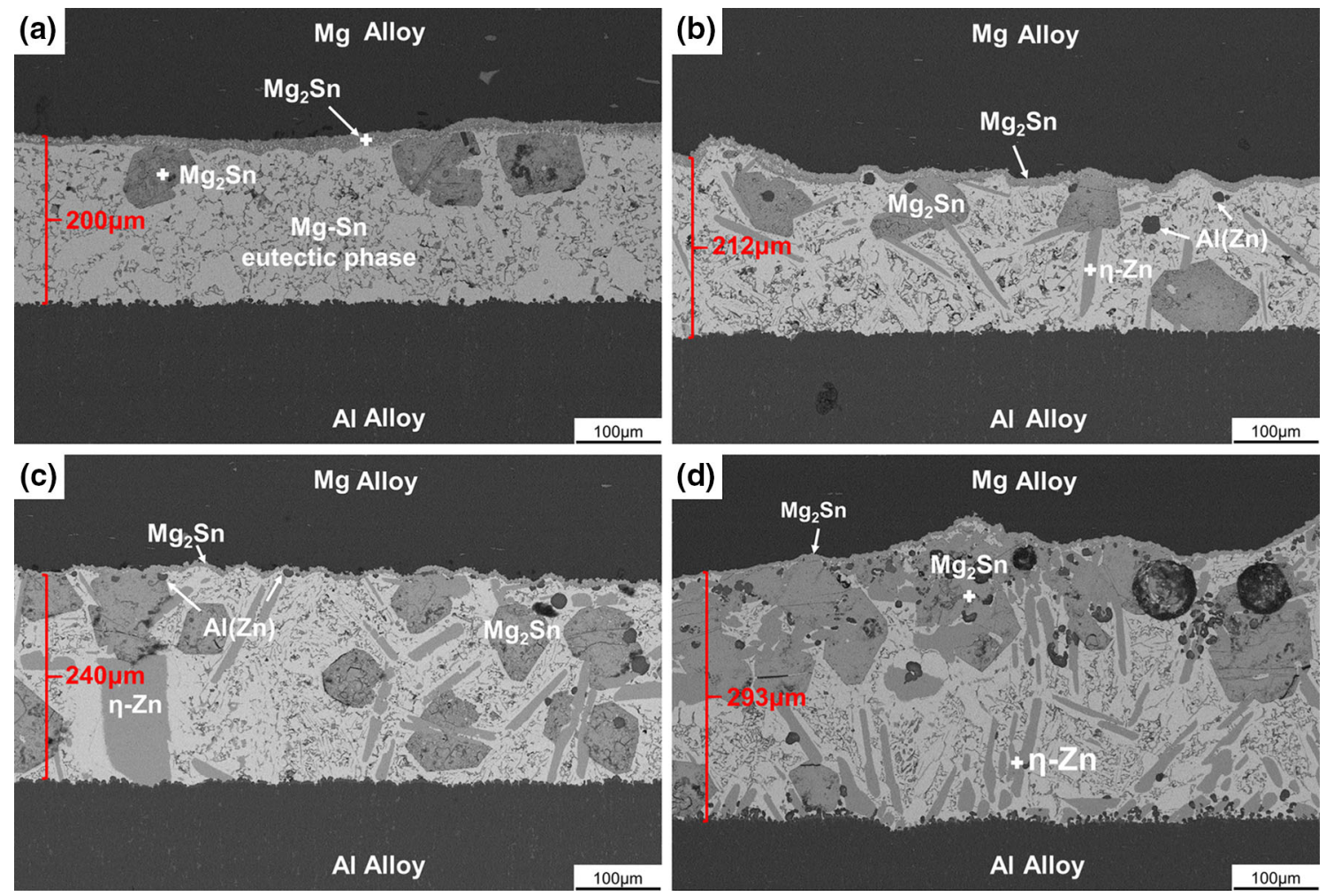

Fig. 3 Microstructures of joint with different $\mathrm{Zn}$ contents: a pure $\mathrm{Sn}(260$

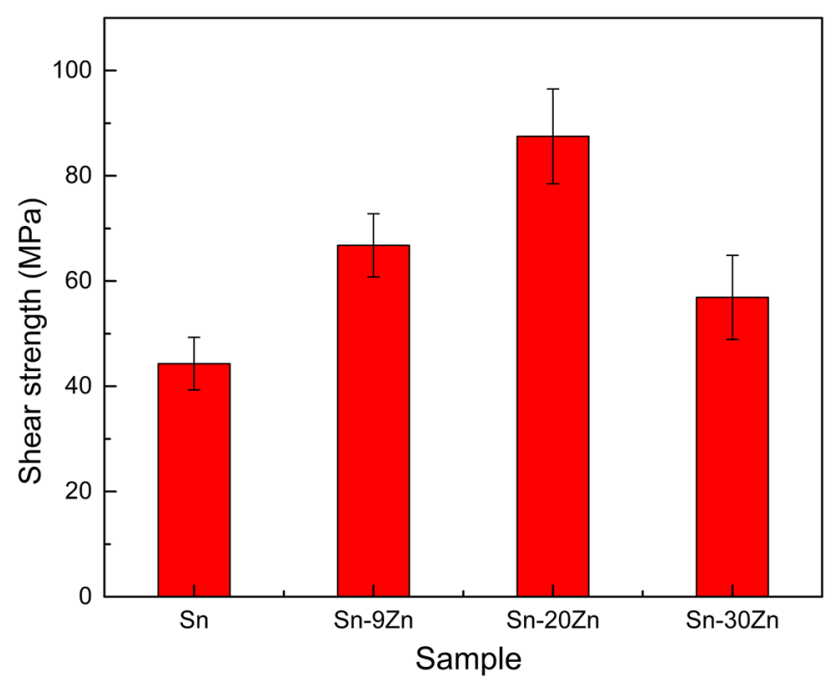

Fig. 4 Shear strength of $\mathrm{Mg} / \mathrm{Al}$ alloy joint with a series of $\mathrm{Sn}-x \mathrm{Zn}$ solders

\subsection{Primary Analysis of Ultrasound Assistance Effect on the Soldering Seam Microstructures}

In order to study the ultrasonic effect on the microstructures of the soldering seam, the soldering process II using $\mathrm{Sn}-20 \mathrm{Zn}$ solder was carried out under the ultrasonic assistance for 1, 3, 5, 10 and $15 \mathrm{~s}$, respectively. As shown in Fig. 5a, the major phases of soldering seam are $\mathrm{Sn}-\mathrm{Zn}$ eutectic structure and $\eta$ - $\mathrm{Zn}$ solid solution. The matrix surface oxide films and air pores are completely removed by the ultrasound assistance for $1 \mathrm{~s}$. Although the breaking behavior of oxide films is not directly observed, the removal mechanism should be similar to our previous study of ultrasonic-assisted brazing for other materials [17, 21-23]. The $\mathrm{Mg}-\mathrm{Sn}$ intermetallic reaction happens as soon as the liquid solder drills into the seam under the effect of ultrasonic pressure; then, a continuous $\mathrm{Mg}_{2} \mathrm{Sn}$ layer is generated attaching to AZ31 Mg alloy.

Figure $5 \mathrm{~b}$ shows the joint microstructure under the ultrasonic assistance for $3 \mathrm{~s}$. It can be seen that the $\mathrm{Mg}_{2} \mathrm{Sn}$ layer starts to shrink and collapse, resulting in the wavy and fragmentary shape on the interfaces. When prolonging ultrasonic assistance time to $5 \mathrm{~s}$, the $\mathrm{Mg}_{2} \mathrm{Sn}$ layer is disintegrated into much smaller fragments and homogeneously distributed in whole soldering seam as shown in Fig. $5 c$, which is mainly attributed to the "acoustic cavitation effect."

The acoustic pressure could be established while the ultrasonic wave transmits across the materials. Since the atoms or molecules in liquid phase or gas phase can move around with little restrain, some micro-region could be torn out, forming an instantaneous bubble when the ultrasonic rarefaction arrives as shown in Fig. 6a. Soon afterward, the bubble rapidly collapses as compression arrives. The 

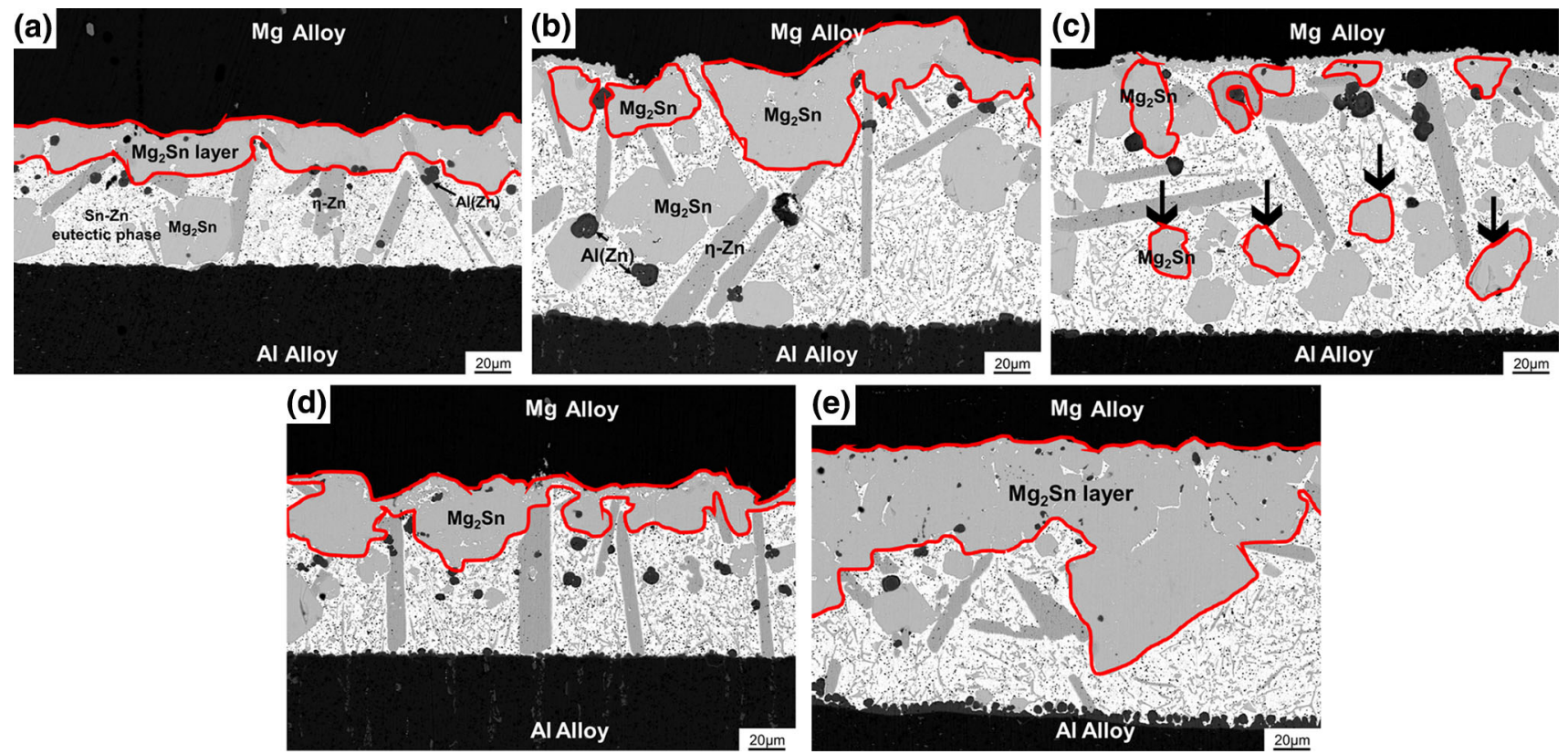

Fig. 5 Microstructures of joints with Sn-20Zn interlayer soldering under different ultrasonic assistance time: a 1 s; b 3 s; c 5 s; d 10 s; e 15 s

bubble implosion can result in a tiny hot spot. The transient temperature of the liquid surrounding the bubble can reach $1600{ }^{\circ} \mathrm{C}$ [29]. Even though the temperature of this spot is extremely high, the tiny volume and transitory duration time of the bubble itself could release heat quickly. When the bubble is closed to the solid phase surface, the bubble would be distorted from spherical to elliptic shape because of the asymmetric pressure at the solid-liquid interface as shown in Fig. 6b, c. This distortion forced the liquid phase to form the microjet, which rushes through the bubble, penetrates the opposite bubble interface and strikes solid surface violently $[16,17,30,31]$ as shown in Fig. 6d.

On the $\mathrm{Mg}$ alloy side interface, a homogeneous $\mathrm{Mg}_{2} \mathrm{Sn}$ IMCs layer is formed (Fig. 7a) under the ultrasonic assistance time for $1 \mathrm{~s}$ and the $\mathrm{Al}$ alloy side interface is flat. Further increasing ultrasonic assistance time to $5 \mathrm{~s}$, the $\mathrm{Mg}_{2} \mathrm{Sn}$ IMCs layer is struck and stripped out by liquid microjet as shown in Fig. 7b, indicating that the ultrasonic wave influences the local environment at the interface between IMCs and liquid solders. In comparison with conventional brazing, the ultrasonic wave assistance could be used as an extra method to intervene the $\mathrm{Mg}-\mathrm{Sn}$ IMCs formation and distribution. The microjet incises and smashes the large continuous IMCs layer into small fragments meanwhile and scatters them into the whole soldering seam. That is beneficial to the joint mechanical properties through the optimization of the brittle IMCs distribution as well as through decrease of the residual stress concentration, especially in the large surface or/and complex structure joining.
However, when applying ultrasonic assistance time for both 10 and $15 \mathrm{~s}$ (Fig. 5d, e), the cracked $\mathrm{Mg}_{2} \mathrm{Sn}$ IMCs become thicken and are filled in almost the entire soldering seam, indicating that too long time of ultrasonic assistance would promote IMCs formation. As shown in Fig. 7c, an increased number of $\mathrm{Mg}_{2} \mathrm{Sn}$ scatter into soldering seam, forming large continuous IMCs when ultrasonic assistance is applied for $15 \mathrm{~s}$. Since the Sn content is sufficient, the $\mathrm{Mg}_{2} \mathrm{Sn}$ could be rapidly formed once $\mathrm{Mg}$ contacts $\mathrm{Sn}$. Meanwhile, the microjet constantly strips $\mathrm{Mg}_{2} \mathrm{Sn}$ out of the $\mathrm{Mg}_{2} \mathrm{Sn}$ layer and moves them away from $\mathrm{Mg}$ alloy side by the acceleration of the convection of substance. With the formation of more $\mathrm{Mg}_{2} \mathrm{Sn}$ IMCs, a lot of space will be filled until the final recrystallization.

A few solder liquid phase and $\mathrm{Al}(\mathrm{Zn})$ solid solution are sealed into several $\mathrm{Mg}_{2} \mathrm{Sn}$ grains, and these $\mathrm{Mg}_{2} \mathrm{Sn}$ IMCs do not form all at once rather than recrystallization when they cool down. Owing to the ultrasonic assistance, the distribution and morphology of these IMCs could be manipulated by controlling ultrasound input time so as to avoid harmful influence of joint mechanical property. The EDS analysis results of possible phases in Fig. 7 are shown in Table 2.

On the $\mathrm{Al}$ alloy side interface, the $\mathrm{Al}(\mathrm{Zn})$ solid solution is formed near $\mathrm{Al}$ side interface as shown in Fig. 7d. A Zn diffusion layer appears on the surface of $\mathrm{Al}$ alloy and becomes thick with the increase of ultrasonic time (Fig. 7e). According to the Al-Zn binary phase diagram, the saturation solid solution of $\mathrm{Al}$ in $\mathrm{Zn}$ was 67 at.\% at $300{ }^{\circ} \mathrm{C}$ [25]; hence, high $\mathrm{Zn}$ content in the solder can 

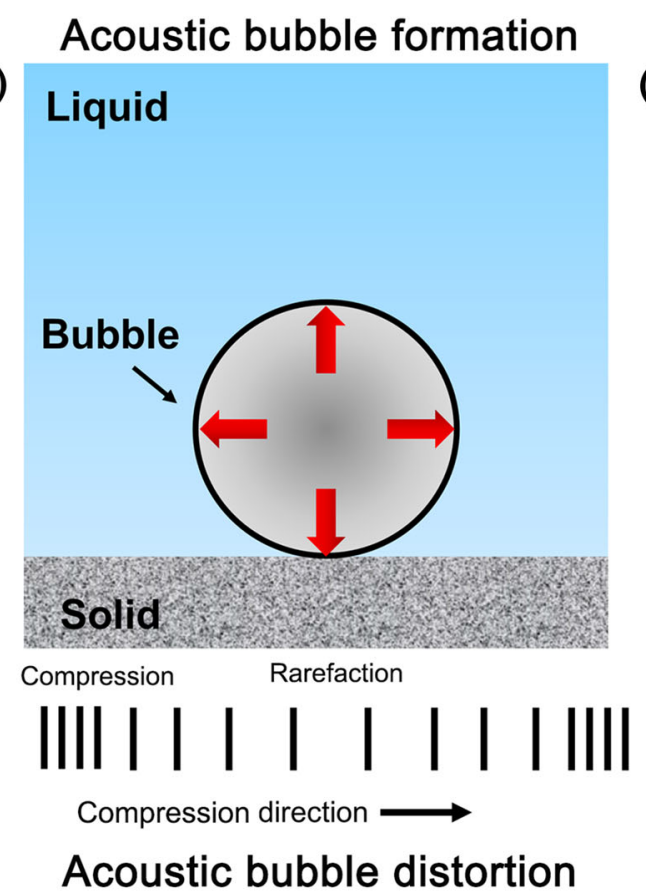

(c)

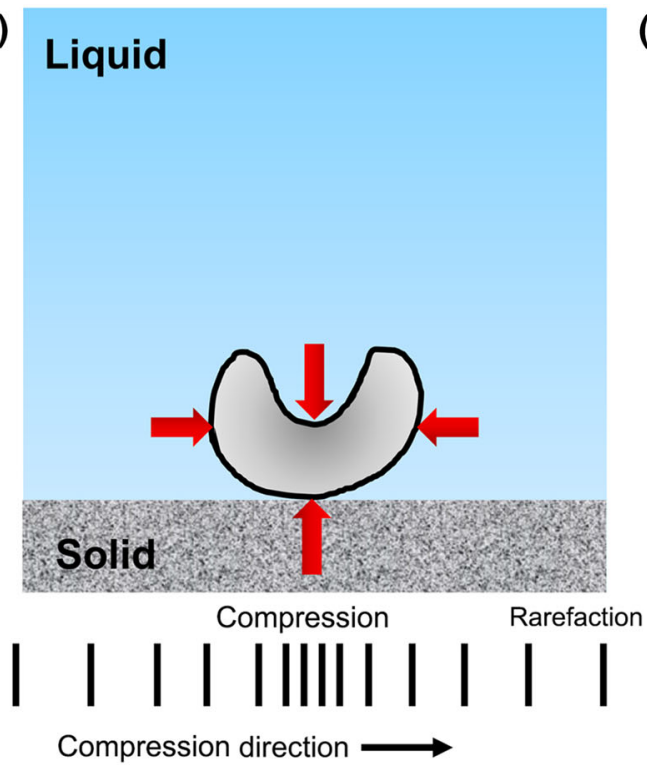

\section{Acoustic bubble compression}

(b)

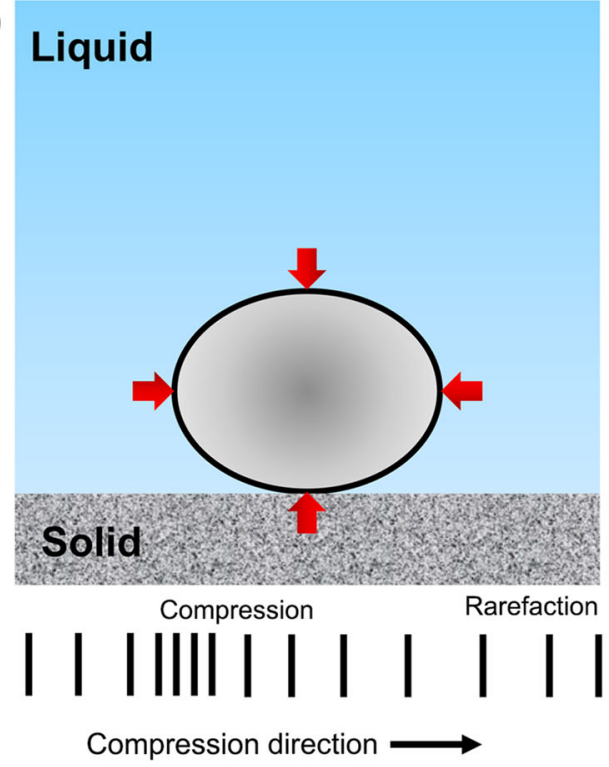

Acoustic bubble collapse

(d)

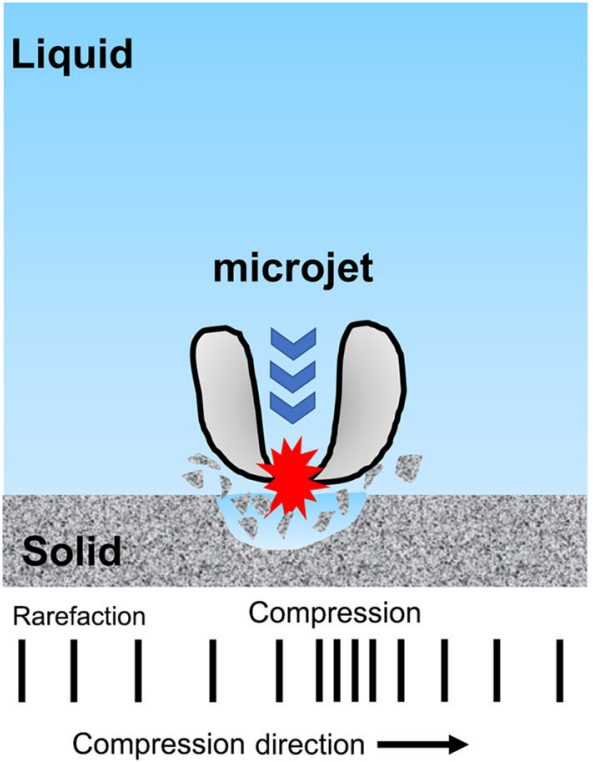

Fig. 6 Diagrams of acoustic cavitation effect: a formation process of acoustic bubble; $\mathbf{b}$ compression process of acoustic bubble; $\mathbf{c}$ distortion process of acoustic bubble; $\mathbf{d}$ collapse process of acoustic bubble

accelerate the $\mathrm{Al}$ grain boundaries dissolution. On the one hand, with the erosion of $\mathrm{Al}$ grain boundaries, the large amount of $\mathrm{Al}$ is dissolved into the liquid $\mathrm{Sn}-20 \mathrm{Zn}$ solder at elevated temperature. The $\mathrm{Al}$ is supersaturated during cooling down and precipitated out as tiny and blocky phase which can be seen in Fig. 7e. On the other hand, the large $\mathrm{Al}(\mathrm{Zn})$ solid solutions are released from the $\mathrm{Al}$ alloy surface and migrate into the soldering seam (Fig. 7f).

\subsection{Joint Mechanical Properties and Fracture Behavior}

The fracture paths of the joints under varied ultrasonic assistance time are mainly classified into two types: (1) fracture into $\mathrm{Mg}_{2} \mathrm{Sn}$ IMCs layer and (2) fracture into soldering seam center. As can be seen in Fig. 8a, c, the joints under ultrasonic assistance for 1 and $15 \mathrm{~s}$ completely fracture within the $\mathrm{Mg}_{2} \mathrm{Sn}$ layer, indicating that these brittle IMCs are the weak region. The large area of $\mathrm{Mg}_{2} \mathrm{Sn}$ IMCs and secondary microcracks can be observed on the fracture 

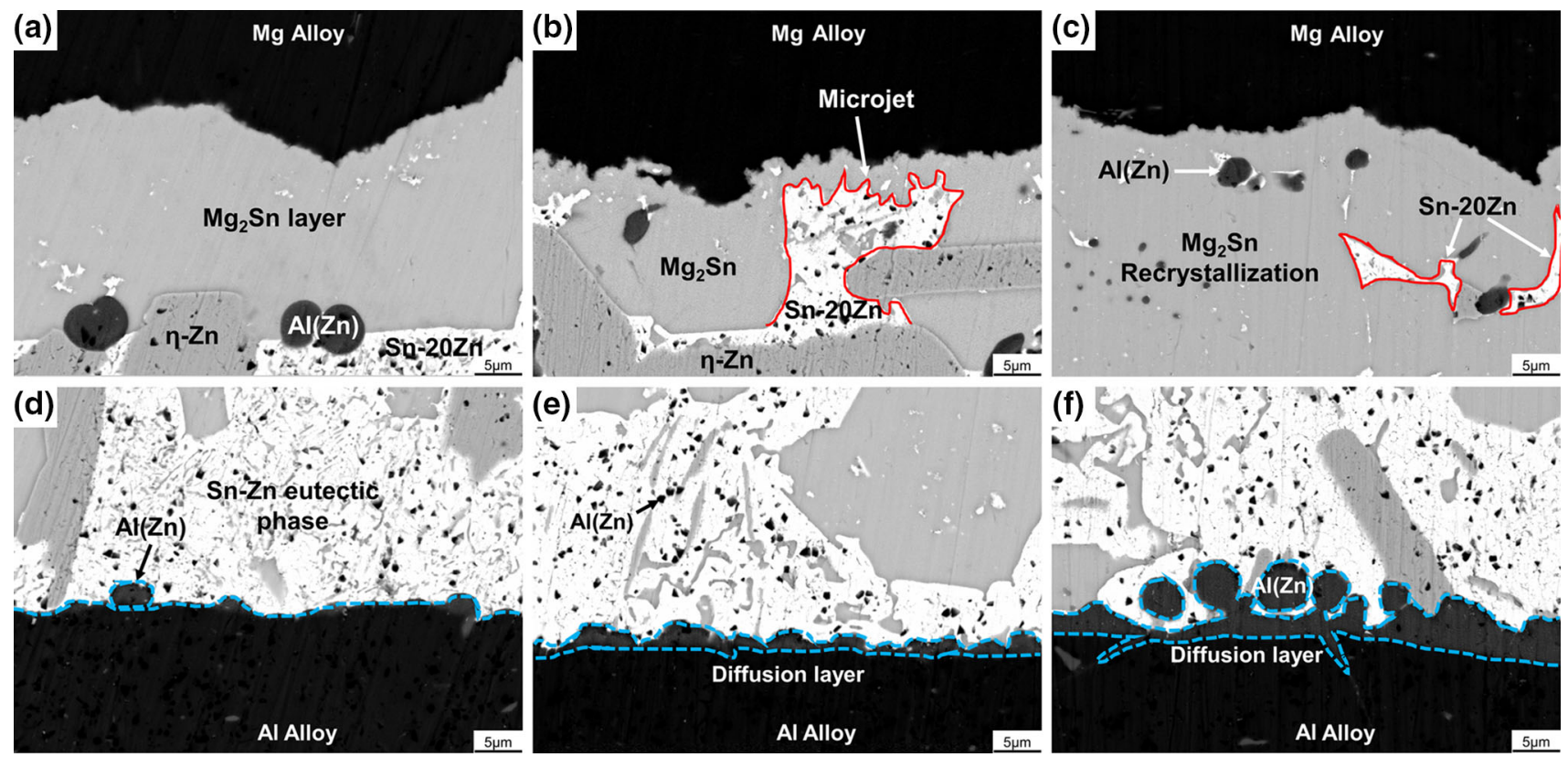

Fig. 7 Magnified microstructures of joints at $\mathrm{Mg} \mathbf{a}-\mathbf{c}$ and $\mathrm{Al} \mathbf{d}-\mathbf{f}$ alloys side interface with ultrasonic assistance time of $1 \mathrm{~s} \mathbf{a}, \mathbf{d}, 5 \mathrm{~s} \mathbf{b}, \mathbf{e}$ and $15 \mathrm{~s}$ c, $\mathbf{f}$

Table 2 EDS results taken from possible phases (at.\%)

\begin{tabular}{lcccc}
\hline Possible phase & $\mathrm{Mg}$ & $\mathrm{Al}$ & $\mathrm{Sn}$ & $\mathrm{Zn}$ \\
\hline $\mathrm{Sn}$ & 4.0 & 4.2 & 88.9 & 2.9 \\
$\eta-\mathrm{Zn}$ & 1.09 & 1.91 & 3.43 & 93.57 \\
$\mathrm{Mg}_{2} \mathrm{Sn}$ & 66.9 & 1.7 & 27.9 & 3.5 \\
$\mathrm{Al}(\mathrm{Zn})$ precipitated phase & 0.8 & 87.9 & 00.4 & 10.6 \\
$\mathrm{Al}(\mathrm{Zn})$ solid solution phase & 0.88 & 92.23 & 1.2 & 6.22 \\
\hline
\end{tabular}

surface as shown in Fig. 9a, b, e, f, which indicates that these IMCs are characteristically brittle in the $\mathrm{Mg}-\mathrm{Sn}$ binary system. The average shear strengths of the joints under ultrasonic assistance for 1 and $15 \mathrm{~s}$ are 73.6 and $54.2 \mathrm{MPa}$ (Fig. 10a), respectively. The XRD pattern (Fig. 10b) shows that all the fracture surfaces contain $\mathrm{Mg}_{2} \mathrm{Sn}$ IMCs. The large residual stress exists since the expansion coefficient of IMCs is much smaller than that of the base materials (Al: $23 \mu \mathrm{m} \mathrm{m}^{-1} \mathrm{~K}^{-1}, \quad \mathrm{Mg}$ : $25 \mu \mathrm{m} \mathrm{m}^{-1} \mathrm{~K}^{-1}$ ) [11]. Thus, when cooling to room temperature, the interface is imposed a tensile stress between $\mathrm{Mg}_{2} \mathrm{Sn}$ and Mg alloys. These brittle IMCs are torn out by the other side of parent material.

However, as shown in Fig. 8b, the fracture path of the joint under ultrasonic assistance for $5 \mathrm{~s}$ completely propagates across the soldering seam center, which could be ascribed to the translation of $\mathrm{Mg}_{2} \mathrm{Sn}$ IMCs morphology from continuous layer into irregular blocky phase. The average shear strength of the joint reaches up to $87.5 \mathrm{MPa}$. As shown in Fig. 9c, d, the fracture surface is mainly consisted of the soldering interlayer microstructures and partial $\mathrm{Mg}_{2} \mathrm{Sn}$ IMCs as well as a small number of $\mathrm{Al}(\mathrm{Zn})$ solid solution. It can be concluded that the distribution and morphology of $\mathrm{Mg}_{2} \mathrm{Sn}$ IMCs determine the mechanical property and fracture behavior of the joints. The continuous
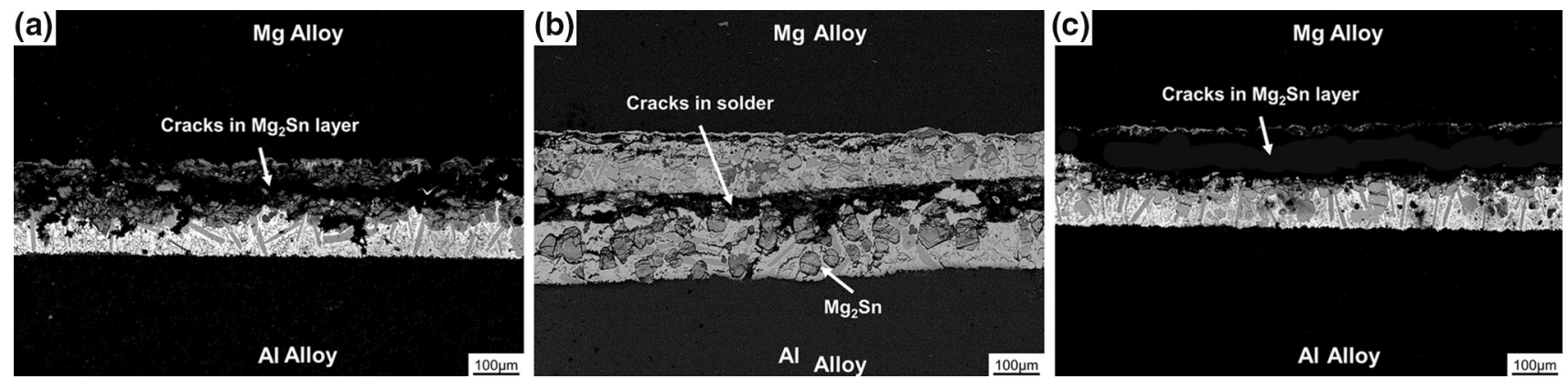

Fig. 8 Joint fracture paths under varied ultrasonic assistance time: a $1 \mathrm{~s}$; b $5 \mathrm{~s}$; c $15 \mathrm{~s}$ 

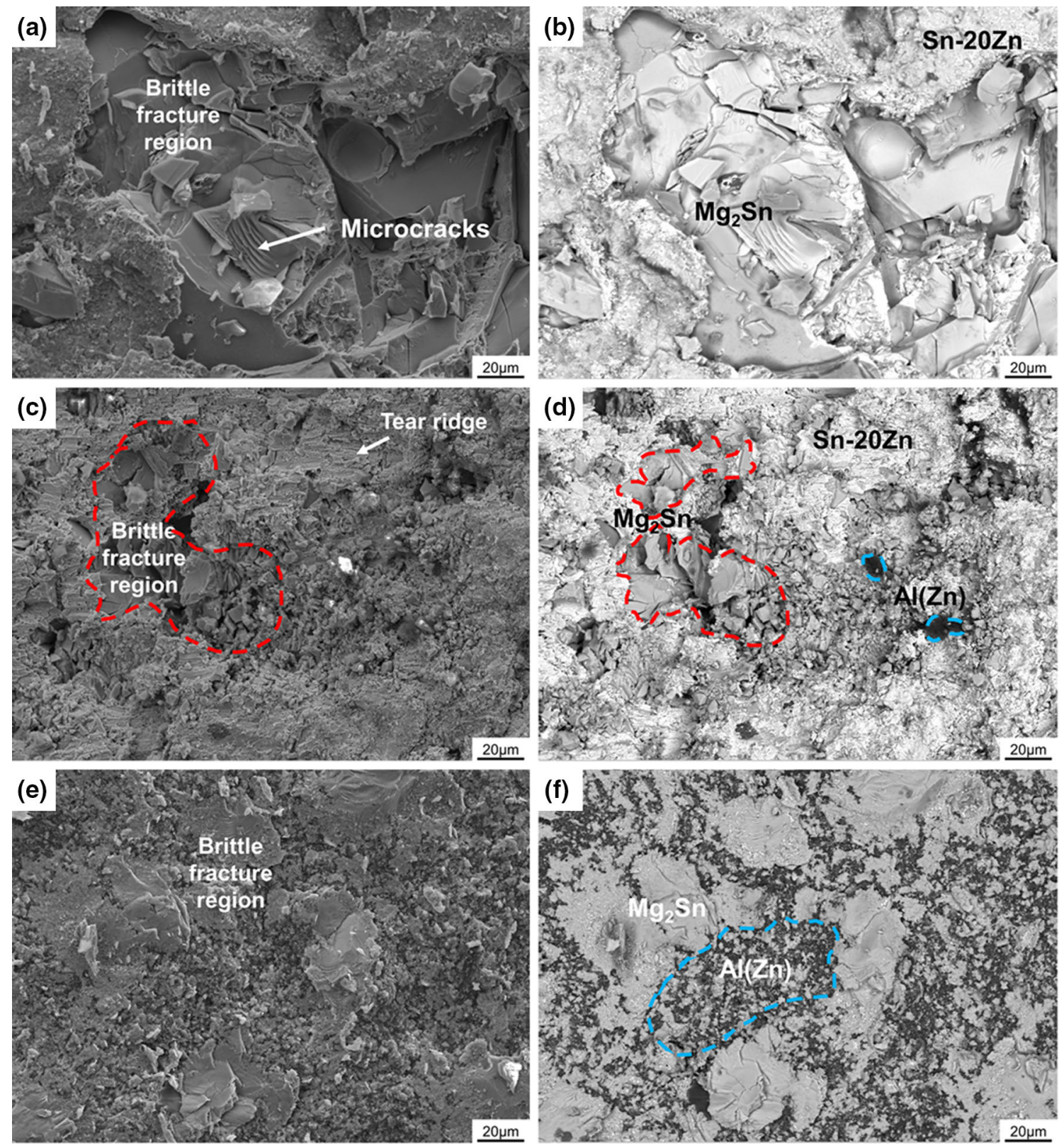

Fig. 9 Secondary electron $\mathbf{a}, \mathbf{c}, \mathbf{e}$ and backscattering electron $\mathbf{b}, \mathbf{d}, \mathbf{f}$ images of Sn-20Zn soldered joint fracture surface with ultrasonic assistance time of $1 \mathrm{~s} \mathrm{a}, \mathbf{b}, 5 \mathrm{~s} \mathbf{c}, \mathbf{d} ; 15 \mathrm{~s} \mathbf{e}, \mathbf{f}$

layer of IMCs is corresponded to lower strength and brittle fracture, while the dispersive blocky IMCs decreasing the stress concentration are corresponded to the higher strength and plasticity fracture.

Another joint strength reinforcement factor is derived from the $\mathrm{Al}(\mathrm{Zn})$ phases, which are mainly existed as two forms as shown in Fig. 11a: (1) the tiny and blocky $\mathrm{Al}(\mathrm{Zn})$ precipitated phase and (2) the large spherical $\mathrm{Al}(\mathrm{Zn})$ solid solution. The $\mathrm{Al}(\mathrm{Zn})$ precipitated phase could strengthen the soldering seam. It has been reported by Li et al. [28] that with applying ultrasonic time for $60 \mathrm{~s}$, some $\mathrm{Al}$ precipitated particles could migrate from the $\mathrm{Al}$ alloy substrate into the bonding seam; hence, the shear strength of joint could be improved from $\sim 40 \mathrm{MPa}$ to $\sim 60 \mathrm{MPa}$ with the increase of $\mathrm{Al}$ particles. Furthermore, the large spherical $\mathrm{Al}(\mathrm{Zn})$ solid solution plays an important role in the reinforcement of strengthening phase interface. As shown in Fig. 11b, the $\mathrm{Al}(\mathrm{Zn})$ solid solution in the brittle $\mathrm{Mg}_{2} \mathrm{Sn}$ IMCs deflects and prevents the propagation of microcracks across the phase interface. It might be attributed to the hindering of the mobility of dislocations and the releasing of stress concentration at the crack tip by the $\mathrm{Al}(\mathrm{Zn})$ solid solution. Zhang and Urbassek [32] studied the dislocationbased strengthening mechanisms of spherical 

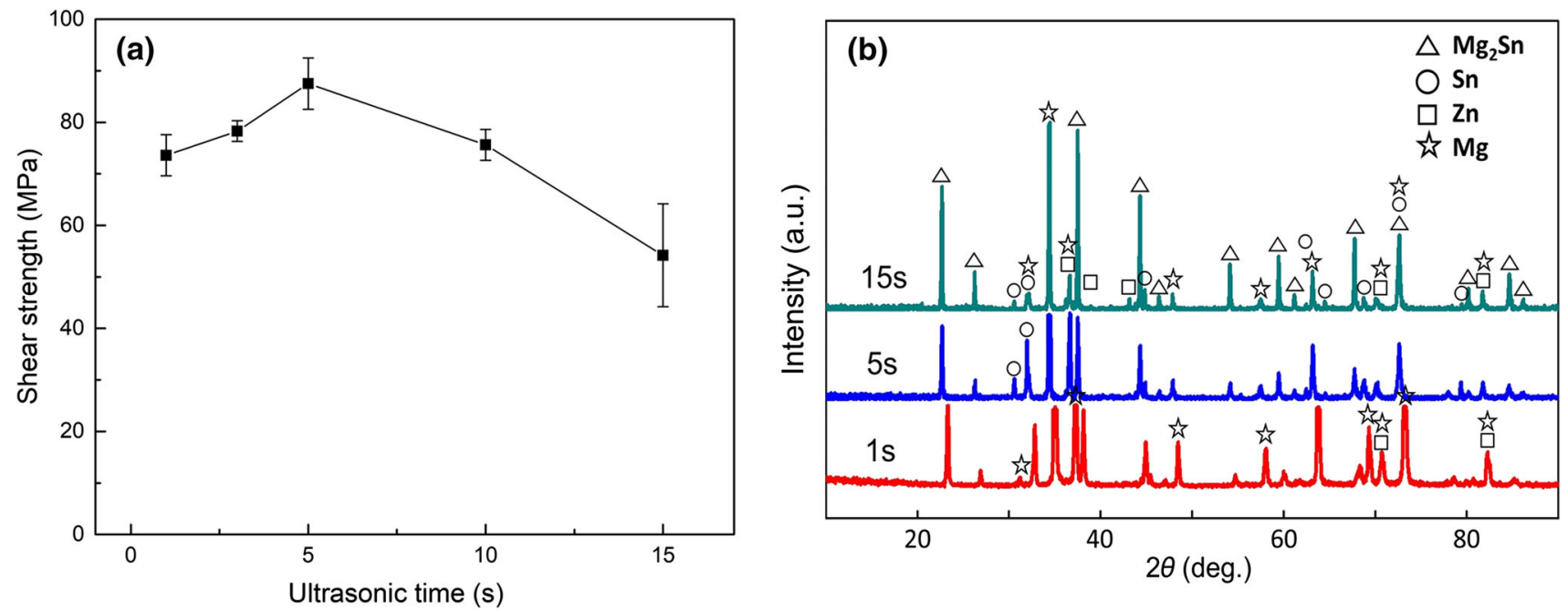

Fig. 10 a Joint shear strength and $\mathbf{b}$ XRD patterns of joint fracture surface with different ultrasonic assistance time
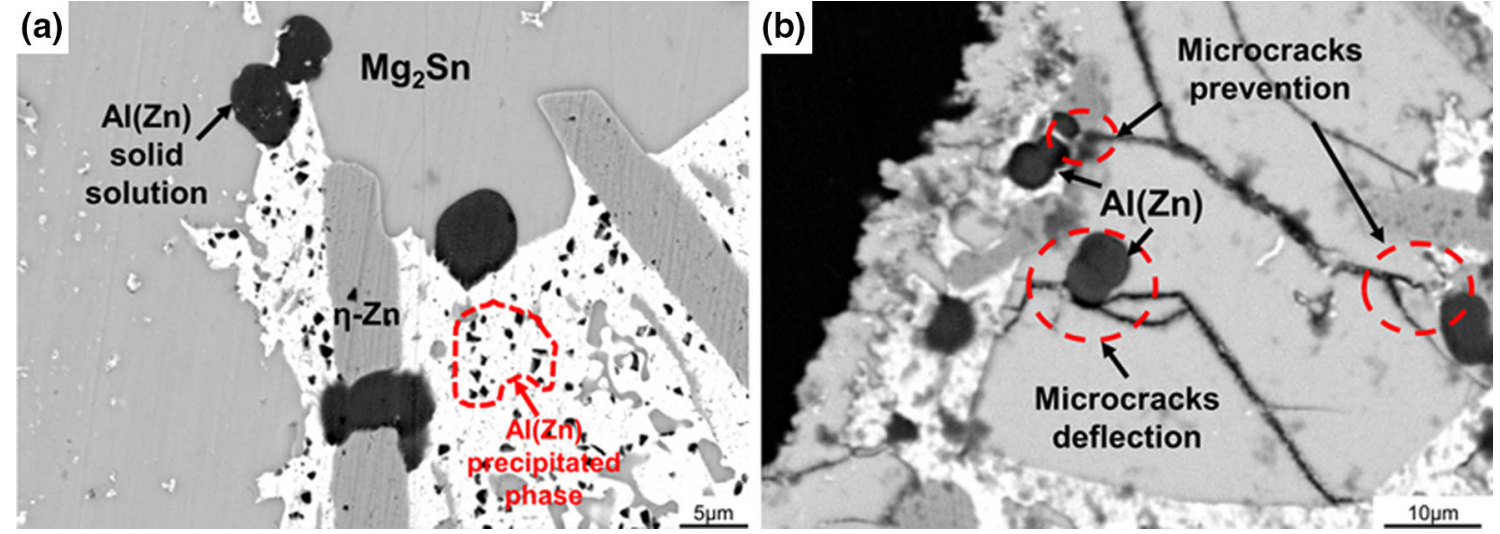

Fig. 11 Morphologies of $\mathrm{Al}(\mathrm{Zn})$ phase distribution $\mathbf{a}$ and microcrack propagation behavior $\mathbf{b}$

reinforcement and pointed out that: (1) The reinforcement influences the direction of motion of the dislocations; (2) the interface swallows part of the dislocations that approach the interface.

\subsection{Model of Ultrasonic Assistance Effect on Joint Formation}

Based on the microstructural observation and analysis, the mechanism of ultrasonic assistance effect on joint formation is summarized in the schematic diagram as shown in Fig. 12. The soldering temperature is constant lower than eutectic reaction points of both $\mathrm{Al}-\mathrm{Mg}$ and $\mathrm{Mg}-\mathrm{Zn}$. The intermetallic reaction only exists in $\mathrm{Mg}-\mathrm{Sn}$ binary system. The $\mathrm{Sn}-\mathrm{Zn}$ eutectic phase still remains in abundance after soldering process according to actual microstructure morphology. As shown in Fig. 12a, a continuous layer of $\mathrm{Mg}_{2} \mathrm{Sn}$ IMCs is immediately formed once the liquid solder drills into the soldering gap at the initial stage of ultrasonic assistance for $1 \mathrm{~s}$. With $\mathrm{Sn}$ content assuming, the residual
Sn-Zn eutectic phase separated out clubbed $\eta$-Zn solid solution and translated into tiny lamellar $\mathrm{Sn}-\mathrm{Zn}$ eutectic phase when cooling down, the reaction formula is as follows:

$$
\begin{aligned}
& \mathrm{L}+\mathrm{Mg} \rightarrow \mathrm{Mg}_{2} \mathrm{Sn}+\mathrm{I}-\mathrm{Sn}-\mathrm{Zn}_{\text {eutectic phase }} \\
& \mathrm{I}-\mathrm{Sn}-\mathrm{Zn}_{\text {eutectic phase }} \rightarrow \eta-\mathrm{Zn}+\mathrm{II}-\mathrm{Sn} \\
&-\mathrm{Zn}_{\text {eutectic phase }}
\end{aligned}
$$

where $\mathrm{I}-\mathrm{Sn}-\mathrm{Zn}_{\text {eutectic }}$ phase represents supersaturated $\mathrm{Zn}$ content $\mathrm{Sn}-\mathrm{Zn}$ eutectic phase and $\mathrm{II}-\mathrm{Sn}-\mathrm{Zn}_{\text {eutectic phase }}$ represents tiny lamellar $\mathrm{Sn}-\mathrm{Zn}$ eutectic phase after separating out $\eta-\mathrm{Zn}$.

The continuous $\mathrm{Mg}_{2} \mathrm{Sn}$ IMCs layer should be thickened as a result of constant sufficient diffusion [8, 11]. However, with prolonging ultrasonic assistance, these layered IMCs are struck by the microjet and splintered into small pieces scattering in liquid solder. The Al alloy side interface becomes wavy because of the erosion of grain boundary, which is ascribed to a certain amount of $\mathrm{Zn}$ content as 


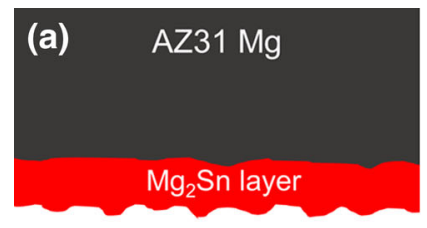

$\mathrm{Sn}-20 \mathrm{Zn}$
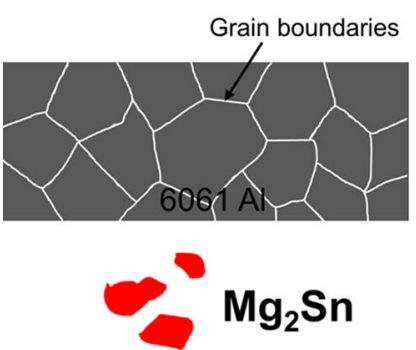
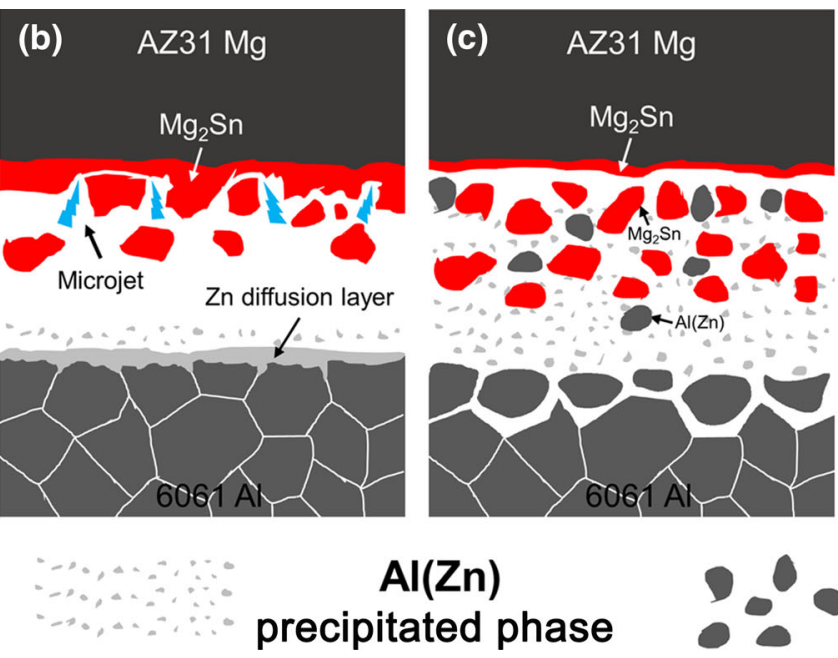

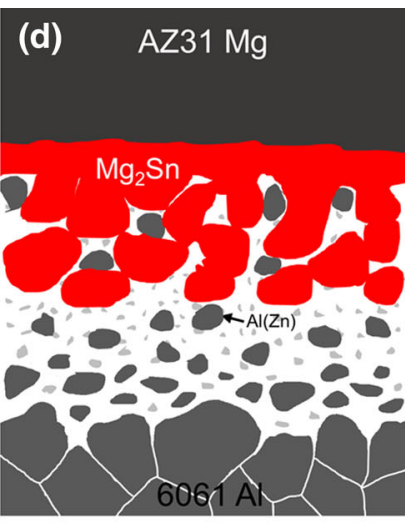

$\mathrm{Al}(\mathrm{Zn})$ solid solution

Fig. 12 Joint formation model of ultrasonic-assisted soldering: a initial state of solders and base materials; $\mathbf{b}$ disintegration of layered $\mathrm{Mg}_{2} \mathrm{Sn}$ IMCs by microjet; $\mathbf{c}$ dispersive distribution of blocky $\mathrm{Mg}_{2} \mathrm{Sn}$ IMCs under ultrasound; $\mathbf{d}$ secondary crystallization of $\mathrm{Mg}_{2} \mathrm{Sn}$ IMCs

shown in Fig. 12b, c. Therefore, the tiny and blocky $\mathrm{Al}(\mathrm{Zn})$ precipitated phases separate out when cooling down. Meanwhile, the large amount of $\mathrm{Al}(\mathrm{Zn})$ solid solutions are released out of the $\mathrm{Al}$ alloy surface, which are migrated to the whole soldering seam by ultrasonic convection. The ultrasonic effect changes the local environment of the interface between $\mathrm{Mg}$ alloy solders and $\mathrm{Al}$ alloy solders, which not only refines and scatters brittle $\mathrm{Mg}_{2} \mathrm{Sn}$ IMCs but also optimizes the $\mathrm{Al}$ dissolution.

Further increasing the time of ultrasonic assistance, the $\mathrm{Mg}_{2} \mathrm{Sn}$ IMCs are constantly splintered out. However, since the $\mathrm{Sn}$ content is sufficient, the $\mathrm{Mg}_{2} \mathrm{Sn}$ IMCs are formed rapidly once $\mathrm{Mg}$ alloy contacts the solder. If the $\mathrm{Mg}_{2} \mathrm{Sn}$ IMCs formation and transition process proceed too long, it could finally fill in the soldering seam. The large amount of $\mathrm{Mg}_{2} \mathrm{Sn}$ IMCs will recrystallize forming a net structure (Fig. 12d) and deteriorate the joint strength.

\section{Conclusion}

The dissimilar AZ31B Mg alloy and $6061 \mathrm{Al}$ alloy were rapidly soldered with $\mathrm{Sn}-x \mathrm{Zn}$ solders at low soldering temperature under the ultrasonic assistance. The $\mathrm{Mg}_{2} \mathrm{Sn}$ IMCs layer, formed on the $\mathrm{Mg}$ side interface, is the weak region of the joints. The $\mathrm{Al}(\mathrm{Zn})$ solid solution formed on the $\mathrm{Al}$ alloy side interface results in a reliable bonding. With the increase of ultrasonic assistance time, the $\mathrm{Mg}_{2} \mathrm{Sn}$ IMCs morphologies changed from continuous layer to dispersing block layer, which enhances the mechanical properties of the joints. The maximum strength of the joints reaches up to $87.5 \mathrm{MPa}$ when they are soldered at temperature of $300{ }^{\circ} \mathrm{C}$ under ultrasonic assistance for only $5 \mathrm{~s}$ using $\mathrm{Sn}-20 \mathrm{Zn}$ solder.
Acknowledgements This work was supported financially by the State Key Laboratory of Advanced Brazing Filler Metals \& Technology (No. SKLABFMT-2016-02), the CAST Innovation Fund Key Project and the National Natural Science Foundation of China (Nos. 51775299 and 51520105007).

\section{References}

[1] W.S. Miller, L. Zhuang, J. Bottema, A.J. Wittebrood, P.D. Smet, A. Haszler, A. Vieregge, Mater. Sci. Eng. A 37, 280 (2000)

[2] J. Liu, K. Zhao, M. Zhang, Y. Wang, L. An, Mater. Lett. 287, 143 (2015)

[3] L. Liu, D. Ren, F. Liu, Materials 373, 67 (2014)

[4] X.D. Qi, L.M. Liu, Mater. Des. 436, 33 (2012)

[5] A. Masoudian, A. Tahaei, A. Shakiba, F. Sharifianjazi, J.A. Mohandesi, Trans. Nonferrous Met. Soc. China 1317, 24 (2014)

[6] G. Mahendran, V. Balasubramanian, T. Senthilvelan, Mater. Des. 1240, 30 (2009)

[7] S.S.S. Afghahi, M. Jafarian, M. Paidar, M. Jafarian, Trans. Nonferrous Met. Soc. China 1843, 26 (2016)

[8] D.M. Fronczek, R. Chulist, L. Litynsk-Dobrzynska, S. Kac, N. Schell, Z. Kania, Z. Szulc, J. Wojewoda-Budka, Mater. Des. 120, 130 (2017)

[9] Z.L. Liu, X.C. Meng, S.D. Ji, Z.W. Li, L. Wang, J. Manuf. Process. 552, 31 (2018)

[10] W.S. Liu, L.P. Long, Y.Z. Ma, L. Wu, J. Alloys Compd. 34, 643 (2015)

[11] Y. Wang, P.B. Prangnell, Mater. Charact. 84, 134 (2017)

[12] L.M. Liu, J.H. Tan, X.J. Liu, Mater. Lett. 2373, 61 (2007)

[13] L.M. Liu, J.H. Tan, L.M. Zhao, X.J. Liu, Mater. Charact. 479, 59 (2008)

[14] Z.W. Xu, L. Ma, J.C. Yan, S.Q. Yang, S.Y. Du, Compos. Part A 407, 43 (2012)

[15] Z. Wang, H. Wang, L. Liu, Mater. Des. 14, 39 (2012)

[16] C.T. Kwok, C.H. Man, F.T. Cheng, Mater. Sci. Eng. A 108, 242 (1998)

[17] X.G. Chen, J.C. Yan, F. Gao, J. Wei, Ultrasonics Sonochem. 144, 20 (2013)

[18] Z.W. Xu, J.C. Yan, G. Wu, X. Kong, S. Yang, Scr. Mater. 835, $53(2005)$ 
[19] Y. Xiao, H.J. Ji, M.Y. Li, J.Y. Kim, H.B. Kim, Mater. Des. 717, 47 (2013)

[20] Y. Zhang, J.C. Yan, X.G. Chen, Y. Cui, Trans. Nonferrous Met. Soc. China 726, 20 (2010)

[21] R.S. Xie, X.G. Chen, Z.W. Lai, L. Liu, G.S. Zou, J.C. Yan, W.X. Wang, Mater. Des. 19, 91 (2016)

[22] Z.Y. Huang, H.Q. Du, L. Liu, Z.W. Lai, X.G. Chen, W.M. Long, W.X. Wang, G.S. Zou, Ultrason. Sonochem. 101, 43 (2018)

[23] Z. Lai, C. Pan, H. Du, X.G. Chen, R.S. Xie, L. Liu, W.M. Long, G.S. Zou, Sci. Technol. Weld. Join. 19, 23 (2018)

[24] W. Guo, T. Luan, J. He, J.C. Yan, Mater. Des. 85, 125 (2017)

[25] X.Y. Yu, W.Q. Xing, M. Ding, Ultrason. Sonochem. 216, 31 (2016)
[26] W. Guo, T.M. Luan, J.S. He, J.C. Yan, Ultrason. Sonochem. 815, 40 (2018)

[27] ASM International Handbook Committee, Properties and Selection: Irons, Steels, and High-Performance Alloys, 10th edn. (ASM International, Materials Park Campus, 1990)

[28] Y. Li, X. Leng, S. Cheng, J. Yan, Mater. Des. 427, 40 (2012)

[29] K.S. Suslick, D.A. Hammerton, R.E. Cline, J. Am. Chem. Soc. 5641, 108 (1986)

[30] X.G. Chen, R.S. Xie, Z.W. Lai, L. Liu, J.C. Yan, G.S. Zou, J. Mater. Sci. Technol. 492, 33 (2017)

[31] E.A. Brujan, P.R. Williams, Chem. Eng. Res. Des. 293, 84 (2006)

[32] Z. Zhang, H.M. Urbassek, Comput. Mater. Sci. 109, 145 (2018) 